\title{
A comparison of failure rates and canal preparation times between WaveOne Gold and One Curve file systems with and without glide path preparation in simulated canals
}

SADJ June 2021, Vol. 76 No. 5 p279 - p283

M Pillay', M Vorster², PJ van der Vyver ${ }^{3}$

\section{ABSTRACT}

\section{Introduction}

The aim of this study was to compare the failure rate and canal preparation times of the Primary WaveOne Gold file (Dentsply Sirona, Ballaigues, Switzerland) with the One Curve file (Micro Méga, Besançon, France). The influence of glide path preparation on failure rate and final preparation times were also evaluated.

\section{Methods}

Endo training blocks (Dentsply Sirona) with simulated canals were separated into four groups: Group 1: Primary WaveOne Gold with WaveOne Gold Glider; Group 2: Primary WaveOne Gold without glide path; Group 3: One Curve with One G; Group 4: One Curve without glide path. The number of training blocks that were shaped before instrument fracture occurred was recorded. Glide path and final preparation times were also recorded.

\section{Results}

Where no glide path was prepared, One Curve file prepared a significantly higher number of canals (14.33 \pm 0.58) than the Primary WaveOne Gold $(4.6 \pm 1.34)$ before instrument fracture occurred $(p<0.001)$. The One

\section{Author affiliations:}

1. Maheshan Pillay: BChD (UWC), PGdipDent (Endo), MSc (Pret), Department of Odontology, School of Dentistry, University of Pretoria, Pretoria, South Africa.

ORCID Number: 0000-0003-1794-7834

2. Martin Vorster: BChD, PG Dip Dent (Endo), MSc (Pret, Department of Odontology, School of Dentistry, University of Pretoria, Pretoria, South Africa.

ORCID Number: 0000-0003-4470-1530

3. Peet J van der Vyver: BChD, PG Dip Dent (Endo), PG Dip Dent (Aesthet Dent), MSc, PhD (Pret), Department of Odontology, School of Dentistry, University of Pretoria, Pretoria, South Africa. ORCID Number: 0000-0003-1951-6042

Corresponding author: Martin Vorster

Department of Odontology, School of Dentistry, University of Pretoria, Gauteng, South Africa.

Email: martin.vorster@up.ac.za

Author contributions:

1. Maheshan Pillay: Principal investigator. Data collection, analysis, scientific writing and editing - $40 \%$

2. Martin Vorster: Scientific writing and editing - $30 \%$

3. Peet $\mathbf{J}$ van der Vyver: Scientific writing and editing - $30 \%$
Curve with One G Glide Path file prepared significantly higher number of simulated canals $(28 \pm 1.41)$ than the Primary WaveOne Gold with WaveOne Gold Glider (15 \pm 1.41) before instrument fracture $(p<0.001)$.

Glide path preparation times with WaveOne Gold Glider (4.8s) were significantly faster compared to the One $G$ Glide Path file (7.29s) $(p<0.001)$. Significantly faster final canal preparation times were achieved in groups where glide path were prepared $(p<0.001)$.

\section{Conclusion}

One Curve files exhibits a greater fracture resistance than Primary WaveOne Gold files. Glide path preparation increases the longevity of preparation files and results in faster final canal preparation.

\section{INTRODUCTION}

Canals with complex anatomy and severe curvatures remain a constant challenge during root canal preparation, increasing the risk for procedural errors. ${ }^{1-3}$ Nickel Titanium (NiTi) files which were developed in the 1980s, have become increasingly popular due to their superior flexibility, effective shaping and enlarging of root canals, minimized ledge formations, perforations and zips compared to traditional stainless steel files. ${ }^{4}$ Despite these advantages, $\mathrm{NiTi}$ files have an increased fracture risk, especially in canals with complex curvatures due to the cyclic fatigue and torsional stresses on these files. ${ }^{5}$

The last decade has seen instrument manufacturers making significant modifications to $\mathrm{NiTi}$ alloy to reduce the incidence of instrument fracture. ${ }^{6}$ Factors such as the alloy, kinematics, metallurgical properties and operational settings of the instrument contribute to fracture resistance. ${ }^{7}$ The Primary WaveOne Gold file (Dentsply Sirona) is a single-file reciprocating system which replaced the NiTi generation of WaveOne instruments. While maintaining the reciprocation motion of files, the cross section, alloy, dimensions and geometry were improved. Files are manufactured from Gold wire by means of using a post- 
manufacturing heating process followed by slow cooling, resulting in high flexibility and a gold color. The cross section is an alternating, off-centred parallelogram with two 85 degree cutting edges. The M-Wire alloy has been changed to Gold wire. The Primary WaveOne Gold instrument has $50 \%$ greater resistance to cyclic fatigue and is $80 \%$ more flexible than the WaveOne Primary file. ${ }^{8}$ The WaveOne Gold files are available in four different tip sizes and tapers 20/07 (Small), 25/07 (Primary), 35/06 (Medium) and 45/05 (Large). ${ }^{9}$

The One Curve (Micro Méga) endodontic file was introduced to the dental market in 2018 as the evolution of the One Shape (Micro Méga) file system. The One Curve file is a single use, single-file system used in continuous rotation motion developed with controlled memory $\mathrm{NiTi}$ alloy technology. One Curve files have an ISO size 25 tip, a constant $6 \%$ taper, with variable cross sections, S-shaped near the shaft and triangular shaped at the tip. ${ }^{10}$ The manufacturer claims that continuous motion with controlled memory alloy technology allows for 33\% faster root canal preparation in comparison to the reciprocating single-file systems and 59\% faster preparation compared to sequential instrumentation. The variable cross section along the instrument blade allows for improved cutting efficiency and centering ability. ${ }^{11}$

The aim of this study was to compare the failure rate as well as canal preparation times of the Primary WaveOne Gold file with the One Curve file. The influence of glide path preparation prior to final canal instrumentation on the fracture rate and preparation times were also evaluated and compared between these two systems.

\section{MATERIALS AND METHODS}

The principles and techniques outlined by Berutti et al. ${ }^{12}$ were used in this study. Four hundred Endo training blocks (Dentsply Sirona) with simulated canals were selected. A working length of $16.5 \mathrm{~mm}$ for each training block was confirmed with a size $10 \mathrm{~K}$-file (Dentsply Sirona). The training blocks were separated into four groups. These groups were: Group 1: Primary WaveOne Gold file in combination with the WaveOne Gold Glider (Dentsply Sirona); Group 2: Primary WaveOne Gold file without any glide path; Group 3: One Curve in combination with One G (Micro Méga) Glide Path file; Group 4: One Curve without any glide path.

Group 1: Primary WaveOne Gold file in combination with the WaveOne Gold Glider

In all training blocks in this group, a pre-curved stainless steel size $10 \mathrm{~K}$-file was negotiated to working length with increasing amplitudes of $1-2 \mathrm{~mm}$ to create an initial manually reproducible glide path. Thereafter the glide path was enlarged with a WaveOne Gold Glider in a reciprocating motion according to the manufacturer's instructions.

After glide path preparation the canals were prepared with a Primary WaveOne Gold file in a reciprocating motion according to the manufacturer's instructions. Final root canal preparation was checked by ensuring that a Primary WaveOne Gold Gutta Percha Cone (25/08) (Dentsply Sirona) could be fitted to full working length.
Group 2: Primary WaveOne Gold file without any glide path

For all training blocks in this group, there was no glide path preparation. The canals were prepared with a Primary WaveOne Gold file in a reciprocating motion according to the manufacturer's instructions. Final root canal preparation was checked by ensuring that a Primary WaveOne Gold Gutta Percha Cone (25/08) could be fitted to full working length.

\section{Group 3: One Curve in combination with One G glide} path file

A pre-curved stainless steel size $10 \mathrm{~K}$-file was negotiated to working length with increasing amplitudes of 1-2 $\mathrm{mm}$ to ensure an initial manually reproducible glide path. Thereafter the glide path was enlarged with a One G Glide path file in a continuous rotation motion, according to the manufacturer's instructions. After glide path preparation the canals were prepared with a One Curve file in a continuous rotation motion, according to the manufacturer's instructions. Final root canal preparation was checked by ensuring that a One Curve Gutta Percha Cone (25/06) (Micro-Mega) could be fitted to full working length.

\section{Group 4: One Curve without any glide path}

For all training blocks in this group, there was no glide path preparation. The canals were prepared with a One Curve file in a continuous rotation motion, according to manufacturer's instructions. Final root canal preparation was checked by ensuring that a One Curve Gutta Percha Cone (25/06) could be fitted to full working length.

All simulated canals were prepared using files with an X-Smart Plus Endo motor (Dentsply Sirona) according to the manufacturer's instructions of each individual file system. Throughout the instrumentation process Glyde Root Canal Conditioner (Dentsply Sirona) was used as a lubricating agent and 3.5\% sodium hypochlorite was used for canal irrigation after the use of each file. All of the preparations were done by one skilled operator. The outcome was measured by recording the number of simulated canals that were prepared by the WaveOne Gold Primary and One Curve instruments, in the glide path group and no glide path group, before failure occurred. This was repeated five times within each group to ensure reliability. All preparation times were recorded with an electronic stopwatch. Canal preparation times for each group was recorded by starting at the point of entry into the canal and stopping the clock at the point of instrument retrieval. The time it took to clean the debris from the instrument flutes, irrigate, re-captitulate and to re-irrigate the canal was not recorded.

\section{Statistical analysis}

IBM SPSS version 25 was used to analyse the data. A pvalue of smaller than 0.05 was considered as statistically significant. The data for the number of simulated canals prepared before file fracture as well as preparation times were compared between the four groups using one-way ANOVA testing, while individual pair-wise group differences were assessed with Bonferroni adjusted t-tests. 


\section{RESULTS}

In the group where no glide path was prepared prior to final canal preparation, the One Curve file prepared a significantly higher number of canals $(14.33 \pm 0.58)$ than the Primary WaveOne Gold (4.60 \pm 1.34$)$ before instrument failure occurred $(p<0.001)$. The One Curve file in combination with the One $G$ Glide Path file prepared a significantly higher number of simulated canals $(28.00 \pm 1.41)$ than the Primary WaveOne Gold in combination with WaveOne Gold Glider $(15.00 \pm 1.41)$ before instrument failure occurred $(p<0.001)$.

Primary WaveOne Gold used in combination with WaveOne Gold Glider (15.00 \pm 1.41$)$ prepared a significantly higher number of simulated canals than the Primary WaveOne Gold without glide path $(4.60 \pm 1.34)$ before instrument failure occurred $(p<0.001)$. The One Curve in combination with One G Glide Path file $(28.00 \pm 1.41)$ prepared a significantly higher number of simulated canals than the One Curve without glide path $(14.33 \pm 0.58)$ before instrument failure occurred $(p<0.001)$.

Glide path preparation times with WaveOne Gold Glider (4.80s) were significantly faster compared to the One G Glide Path file $(7.29 \mathrm{~s})(\mathrm{p}<0.001)$. There was no significant difference in canal preparation times between the Primary WaveOne Gold without glide path group compared to the One Curve without glide path group $(p=1.000)$.

Similarly, there was no significant difference in canal preparation times between the Primary WaveOne Gold in combination with WaveOne Gold Glider group compared to the One Curve in combination with One G Glide Path file group $(p=1.000)$.

Significantly faster canal preparation times were achieved with the Primary WaveOne Gold group with prior glide paths prepared with WaveOne Gold Glider (17.60s) compared to the Primary WaveOne Gold group without glide path $(22.48 s)(p<0.001)$. Similarly, significantly faster canal preparation times were achieved by the One Curve group with prior glide paths (16.78s) prepared with One G Glide Path file compared to the One Curve group without glide path (23.49s) $(p<0.001)$.

\section{DISCUSSION}

Clinicians are faced with the challenge to provide faster, more efficient, cost effective treatment whilst maintaining sterile conditions. Hurrying root canal treatment together with disrespecting the limitation of NiTi rotary instruments increases the risk of instrument failure. ${ }^{13}$ Instrument fracture within a root canal may prevent the disinfection of the canal, which may compromise the outcome of the endodontic treatment. ${ }^{14}$

Glide path preparation enables the acquisition of canal patency, facilitates the use of rotary files and results in increased efficacy of root canal preparation. ${ }^{12,15}$ Patino et al. ${ }^{16}$ reported a reduced incidence of instrument fracture in canals where there was glide path preparation prior to preparation of the root canal with rotary instruments. Another study by Shen et al. ${ }^{17}$ reported a higher incidence of fracture and distortion of NiTi files where there was no prior glide path preparation.

According to the results of this study it can be concluded that the presence of a glide path significantly influenced the number of simulated canals prepared. When no initial glide path was created, the One Curve prepared a significantly higher number of simulated canals (14.33 \pm 0.58 ) compared to the Primary WaveOne Gold (4.60 $\pm 1.34)$ before instrument fracture occurred $(p<0.001)$. When a prior glide path was created with One G Glide Path file, One Curve prepared a significantly higher number of simulated canals $(28.00 \pm 1.41)$ before instrument fracture occurred compared to the Primary WaveOne Gold when prior glide path preparation was created with Wave One Gold Glider $(15.00 \pm 1.41)(p<0.001)$.

\begin{tabular}{|c|c|c|c|c|}
\hline Group & Mean(s) & $\begin{array}{l}\text { Standard } \\
\text { Deviation }\end{array}$ & $\begin{array}{c}\text { Coefficient of Variation } \\
(\%)\end{array}$ & $\begin{array}{l}\text { 95\% Confidence } \\
\text { Interval }\end{array}$ \\
\hline Primary WaveOne Gold without glide path & $4.60^{\mathrm{a}}$ & 1.34 & 29.13 & $(3.43 ; 5.77)$ \\
\hline Primary WaveOne Gold with WaveOne Gold Glider & $15.00^{\mathrm{b}}$ & 1.41 & 9.40 & $(13.05 ; 16.95)$ \\
\hline One Curve without glide path & $14.33^{\mathrm{b}}$ & 0.58 & 4.05 & $(13.67 ; 14.99)$ \\
\hline One Curve with One G Glide Path file & $28.00^{\circ}$ & 1.41 & 5.04 & $(26.05 ; 29.95)$ \\
\hline \multicolumn{5}{|c|}{ Mean values with the same superscript letters were not statistically different at $p<0.05$} \\
\hline Group & Mean(s) & $\begin{array}{l}\text { Standard } \\
\text { Deviation }\end{array}$ & $\begin{array}{l}\text { Coefficient of Variation } \\
(\%)\end{array}$ & $\begin{array}{l}95 \% \text { Confidence } \\
\text { Interval }\end{array}$ \\
\hline Primary WaveOne Gold without glide path & $22.45^{\mathrm{a}}$ & 4.17 & 18.55 & $(20.52 ; 24.38)$ \\
\hline Primary WaveOne Gold with WaveOne Gold Glider & $17.60^{\mathrm{b}}$ & 2.78 & 15.8 & $(16.57 ; 18.63)$ \\
\hline One Curve without glide path & $23.49^{a}$ & 3.80 & 16.18 & $(22.35 ; 24.63)$ \\
\hline One Curve with One G Glide Path file & $16.78^{\mathrm{b}}$ & 2.12 & 12.63 & $(16.21 ; 17.35)$ \\
\hline Group & Mean(s) & $\begin{array}{l}\text { Standard } \\
\text { Deviation }\end{array}$ & $\begin{array}{l}\text { Coefficient of Variation } \\
\qquad(\%)\end{array}$ & $\begin{array}{l}\text { 95\% Confidence } \\
\text { Interval }\end{array}$ \\
\hline WaveOne Gold Glider & $4.80^{\mathrm{a}}$ & 1.23 & 25.63 & $(4.2 ; 5.4)$ \\
\hline One G Glide Path File & $7.29^{b}$ & 1.06 & 14.54 & $(6.77 ; 7.81)$ \\
\hline
\end{tabular}


Statistically significant differences existed between the mean values for the number of simulated canals that could be prepared with the One Curve file compared to the Primary WaveOne Gold file. In previous studies, instruments manufactured from controlled memory were reported to demonstrate higher resistance to cyclic fatigue/instrument failure than those manufactured from conventional $\mathrm{NiTi}$ alloy. ${ }^{14,18,19}$

When a prior glide path was prepared with WaveOne Gold Glider, the Primary WaveOne Gold prepared more simulated canals $(15.00 \pm 1.41)$ than the Primary WaveOne Gold without prior glide path preparation $(4.60 \pm 1.34)$ before instrument fracture occurred $(p<0.001)$. Similarly, One Curve prepared more simulated canals $(28.00 \pm 1.41)$ when prior glide path preparation was created with One G Glide Path file than the One Curve without prior glide path preparation $(14.33 \pm 0.58)$ before instrument fracture occurred $(\mathrm{p}<0.001)$.

According to the results of this study, when no prior glide path was created a mean of only 4.60 and 14.33 simulated canals could be prepared before instrument fracture with Primary WaveOne Gold and One Curve files respectively. When a prior glide path was created a mean of 15.00 and 28.00 simulated canals could be prepared with Primary WaveOne Gold and One Curve files respectively. Statistically significant differences were observed when mean values for the number of simulated canals with prior glide path preparation were compared to canals without prior glide path preparation.

Within the limitations of this study, it is evident that glide path preparation has a considerable influence on instrument efficacy, increasing the longevity of the Primary WaveOne Gold and One Curve instruments and enabling a greater number of simulated canals to be prepared before instrument failure. These findings are consistent with the findings of similar studies. ${ }^{13,20}$

The results of this study further demonstrates that the One Curve file can prepare a significantly higher mean number of simulated canals before fracture occurred compared to the Primary Wave-One Gold file. This result contrasts with the findings of a study by Yilmaz et al. ${ }^{11}$ in which the One Curve file demonstrated the lowest cyclic fatigue resistance compared to the Hyflex EDM (Coltene/ Whaledent), WaveOne Gold and RPC Blue (VDW) file systems, however it must be noted that the One Curve files were used at $450 \mathrm{rpm}$ and $2.5 \mathrm{gcm}^{-1}$ compared to this study where the files were used at $300 \mathrm{rpm}$ and $2.5 \mathrm{~N} . \mathrm{cm}$ as per the manufacturer's instructions.

The results of this study showed the One Curve instrument to have a greater fracture resistance compared to the Primary WaveOne Gold. Similarly, Serafin et al. ${ }^{10}$ reported the One Curve instrument to resist cyclic fatigue 2.4 times more than the One Shape instrument. Serafin et al. $^{10}$ postulated that the heat treatment of the NiTi alloy, file diameter and cross section may be the reasons for improved resistance of One Curve to cyclic fatigue.

Galal $^{21}$ concluded that the increase in flexibility and torsional resistance of controlled memory files can be attributed to the metallurgical improvement of the files.
Comparative studies of endodontic instruments manufactured with CM Wire, conventional alloys and M-Wire have shown CM Wire to possess significantly greater cyclic fatigue resistance than the others. ${ }^{14,22,23}$

The minimised contact area from the shaft of $6 \%$ taper of the One Curve as compared to the $7 \%$ variable taper of the Primary WaveOne Gold must also be taken into consideration when analysing the results. Previous studies have reported that smaller instruments exhibited increased flexibility and cyclic fatigue resistance..$^{24,25}$

The results of this study showed that glide path preparation times with the WaveOne Gold Glider (4.80s) were significantly faster compared to the One G Glide Path file $(7.29 \mathrm{~s})(\mathrm{p}<0.001)$. A study by Vorster et al. ${ }^{26}$ showed similar results, reporting the WaveOne Glider to be faster than other glide path preparation techniques.

When there was no initial glide path prepared, there was no significant difference in preparation times between the Primary WaveOne Gold and One Curve files $(p=1.000)$. Similarly, there was no significant difference in preparation times when an initial glide path was prepared between the Primary WaveOne Gold in combination with WaveOne Gold Glider group and the One Curve in combination with One G Glide Path file group $(p=1.000)$. No comparative data on the preparation times between Primary WaveOne Gold and One Curve instruments could be found in the literature.

The results of this study also demonstrated that the preparation time to prepare a simulated canal with Primary WaveOne Gold when an initial glide path was created with WaveOne Gold Glider (17.60s) was significantly faster compared to preparation with the WaveOne Gold without prior glide path preparation $(22.45 s)(p<0.001)$. This result is consistent with the findings of Vorster et al. ${ }^{26}$ where final shaping times with Primary WaveOne Gold were significantly longer in the groups where no initial glide path was prepared. Similarly, a significantly faster preparation time was achieved by the One Curve group with initial glide path created with One G Glide Path file (16.78s) compared to the One Curve group without prior glide path preparation $(23.49 s)(p<0.001)$. Similar findings have been made in other studies comparing canal preparation with and without initial glide path. ${ }^{26,27}$

\section{CONCLUSION}

Within the limitations of this study, it can be concluded that the rotating One Curve instrument resisted instrument failure better than the reciprocating Primary WaveOne Gold instrument in simulated canals, with and without prior glide path preparation.

The presence of prior glide path preparation enabled a significantly greater number of simulated canals to be prepared before instrument failure, for both Primary WaveOne Gold and One Curve instruments. The presence of prior glide path preparation also significantly reduced simulated canal preparation times with both Primary WaveOne Gold and One Curve instruments. 


\section{References}

1. Peters OA, Paque F. Current developments in rotary root canal instrument technology and clinical use: a review. Quintessence Int. 2010; 41(6): 479-88.

2. Mandel E, Adib-Yazdi M, Benhamou LM, Lachkar T, et al. Rotary $\mathrm{Ni}$-Ti profile systems for preparing curved canals in resin blocks: influence of operator on instrument breakage. Int Endod J. 1999; 32(6): 436-43.

3. Weine FS, Kelly RF, Lio PJ. The effect of preparation procedures on original canal shape and on apical foramen shape. $J$ Endod. 1975; 1(8): 255-62.

4. Arias A, Perez-Higueras JJ, de la Macorra JC. Differences in Cyclic Fatigue Resistance at Apical and Coronal Levels of Reciproc and WaveOne New Files. J Endod. 2012; 38(9): 1244-8.

5. Walia HM, Brantley WA, Gerstein H. An initial investigation of the bending and torsional properties of Nitinol root canal files. J Endod. 1988; 14(7): 346-51.

6. McGuigan MB, Louca C, Duncan HF. Endodontic instrument fracture: causes and prevention. Br Dent J. 2013; 214(7): 341-8.

7. Kitchens GG, Jr., Liewehr FR, Moon PC. The effect of operational speed on the fracture of nickel-titanium rotary instruments. J Endod. 2007; 33(1): 52-4.

8. JW. Shaping canals with confidence: WaveOne Gold single-file. Roots. 2015; 1: 34-40.

9. Ruddle C. Single-file shaping technique: achieving a gold medal result. Dent Today. 2016; 35(198): 100, 2-3.

10. Serafin M, De Biasi M, Franco V, Angerame D. In vitro comparison of cyclic fatigue resistance of two rotary single-file endodontic systems: OneCurve versus OneShape. Odontology. 2019; 107(2): 196-201.

11. Yılmaz K, Özyürek T, Uslu G. Comparision of Cyclic Fatigue Resistance of One Curve, Hyflex EDM, WaveOne Gold and Reciproc Blue Nickel-Titanium Rotary Files at Intra-canal Temperature. Cumhur Dent J. 2019; 22: 42-7.

12. Berutti E, Negro AR, Lendini M, Pasqualini D. Influence of manual preflaring and torque on the failure rate of ProTaper rotary instruments. J Endod. 2004; 30(4): 228-30.

13. Jonker $\mathrm{CH}$, De Wet FA, Van der Vyver PJ. The influence of $g$ lide path preparation on the failure rate of WaveOne reciprocating instruments. SADJ. 2014; 69(6): 266-9.

14. Capar ID, Kaval ME, Ertas H, Sen BH. Comparison of the cyclic fatigue resistance of 5 different rotary pathfinding instruments made of conventional nickel-titanium wire, $\mathrm{M}$-wire, and controlled memory wire. J Endod. 2015; 41(4): 535-8.

15. Knowles KI, Hammond NB, Biggs SG, Ibarrola JL. Incidence of Instrument Separation Using LightSpeed Rotary Instruments. J Endod. 2006; 32(1): 14-6.

16. Patiño PV, Biedma BM, Liébana CR, Cantatore G, et al. The Influence of a Manual Glide Path on the Separation Rate of NiTi Rotary Instruments. J Endod. 2005; 31(2): 114-6.

17. Shen Y, Haapasalo M, Cheung GS, Peng B. Defects in nickeltitanium instruments after clinical use. Part 1: Relationship between observed imperfections and factors leading to such defects in a cohort study. J Endod. 2009; 35(1): 129-32.

18. Plotino G, Testarelli L, Al-Sudani D, Pongione G, et al. Fatigue resistance of rotary instruments manufactured using different nickel-titanium alloys: a comparative study. Odontology. 2014; 102(1): 31-5

19. Peters OA, Gluskin AK, Weiss RA, Han JT. An in vitro assessment of the physical properties of novel Hyflex nickel-titanium rotary instruments. Int Endod J. 2012; 45(11): 1027-34.

20. Kwak SW, Ha JH, Cheung GS, Kim HC, et al. Effect of the Glide Path Establishment on the Torque Generation to the Files during Instrumentation: An In Vitro Measurement. J Endod. 2018; 44(3): 496-500.

21. Manar G. Metallurgical effect on the mechanical behavior of rotary endodontic files using finite element analysis. Bulletin of the National Research Centre. 2019; 43(1): 1-5.
22. Inojosa IdFdAJ, Lopes HP, Pereira PLR, Nascimento DLd, et al. Fatigue resistance of endodontic instruments manufactured in NiTi CM Wire and in conventional NiTi alloy with eletrochemical treatment. Resistência à fadiga de instrumentos endodônticos fabricados em NiTi CM Wire e em niti convencional com tratamento eletroquìmico. 2018;66(2):111-6.

23. Braga LCMDDSMS, Faria Silva ACDDSMS, Buono VTLBSM SP, de Azevedo Bahia MGDDSMSP. Impact of Heat Treatments on the Fatigue Resistance of Different Rotary Nickeltitanium Instruments. J Endod. 2014; 40(9): 1494-7.

24. Plotino G, Grande NM, Cotti E, Testarelli L, et al. Blue Treatment Enhances Cyclic Fatigue Resistance of Vortex NickelTitanium Rotary Files. J Endod. 2014; 40(9): 1451-3.

25. Pruett JP, Clement DJ, Carnes DL. Cyclic fatigue testing of nickel-titanium endodontic instruments. J Endod. 1997; 23(2): 77-85.

26. Vorster M, van der Vyver PJ, Paleker F. Influence of Glide Path Preparation on the Canal Shaping Times of WaveOne Gold in Curved Mandibular Molar Canals. J Endod. 2018; 44(5): 853-5.

27. Coelho MS, Fontana CE, Kato AS, de Martin AS, et al. Effects of Glide Path on the Centering Ability and Preparation Time of Two Reciprocating Instruments. Iran Endod J. 2016; 11(1): 33-7. 